\title{
Copyright's Illogical Exclusion of Conceptual Art*
}

\author{
Zahr K. Said**
}

Many conceptual artists creating art in the contemporary era rebel against staid notions of what art can be, by using found, recycled, nontraditional, or natural materials. ${ }^{1}$ For example, noted photographer and sculptor Andy Goldsworthy works only with natural materials, typically found outside, and transformed through use of his hands, teeth, and found tools: "His raw material is the natural world. He balances slivers of sandstone, slate, and oak into improbable cairns; painstakingly fuses sycamore leaves and horse-chestnut stalks into filigree shapes; molds humpback sculptures out of sand; and fashions giant snowballs that gently melt to reveal pebbles, pine needles, and twigs." ${ }^{2}$ He writes: "[I] can't edit the materials I work with. My remit is to work with nature as a whole." 3 Goldsworthy's artistic mission, in other words, is to work with materials in the natural world with the understanding that they will decay, or last only ephemerally.

Often, conceptual art like this appears as an installation that may be fleeting or time-limited, underscoring modern art's difference from traditional forms of art that might have been hung in museums or otherwise displayed in some stable, relatively unchanging form created to exist for long periods of time. By using innovative kinds of materials, and calling into question whether art must-and can-last, conceptual artists create works that would seem to fall outside the scope of federal copyright protection. ${ }^{4}$ This is largely because when conceptual art exists in a form that is improvisational, changing and transitory, or decaying, it appears to fail to satisfy copyright's "fixation" requirement. ${ }^{5}$ Section 102(a) of the Copyright Act of

* This Essay is based on a talk that was given on October 2, 2015, at the Kernochan Center Annual Symposium at Columbia Law School.

** Associate Professor of Law, University of Washington School of Law. My thanks to Jane Ginsburg for inviting me to present this paper at the Kernochan Center Symposium, "Copyright Outside the Box." Thanks also to the panelists and participants at the symposium.

1. Charles Cronin, Dead on the Vine: Living and Conceptual Art and VARA, 12 VAND. J. ENT. \& TECH. L. 209, 213-14 (2010).

2. Alistair Sooke, He's got the whole world in his hands, DAily TelegraPh (Mar. 24, 2007), http://www.telegraph.co.uk/culture/art/3663966/Hes-got-the-whole-world-in-his-hands.html [perma.cc/G9ML-5KMQ].

3. Id.

4. State copyright law may still provide protection on a state-by-state basis for some art that falls outside of federal copyright law. 17 U.S.C. § 301(b)(1) (2012) (declining to preempt state protection for unfixed works of art).

5. I say "largely" because it is also possible for conceptual art to fall outside of copyright protection for numerous other reasons, such as the useful articles doctrine. See generally, Brandir Int'l v. Cascade Pac. Lumber Co., 834 F.2d 1142 (2d Cir. 1987). For a discussion on the limitations of what counts as copyrightable subject matter, see Kelley v. Chi. Park Dist., 635 F.3d 290, 303-05 (7th Cir. 
1976 requires that "original works of authorship [be] fixed in any tangible medium of expression, now known or later developed, from which they can be perceived, reproduced, or otherwise communicated, either directly or with the aid of a machine or device." The Copyright Act defines a work as "'fixed' in a tangible medium of expression when its embodiment in a copy ... by or under the authority of the author, is sufficiently permanent or stable to permit it to be perceived, reproduced, or otherwise communicated for a period of more than transitory duration." 7

Typically, works of art are fixed in some form, such as wood, canvas, or clay, for example; it is thus easy for most works to meet copyright's fixation requirement. ${ }^{8}$ Hence, there is comparatively scant case law on how to apply the fixation requirement, other than in computer cases where digital technology once presented some difficult questions for the application of the fixation requirement. ${ }^{9}$ Despite the lack of case law addressing current live issues, there remain open questions as to when fixation can and does cut off copyright protection for works of conceptual, improvisational, or theatrical art. ${ }^{10}$ When works of art are improvisational, for instance, they fail to qualify for protection unless they are recorded, photographed, or in some other way literally "fixed."11 Similarly, works that frequently change or that are designed to decay would seem, facially, to fail to meet the fixation requirement. Like improvisational works, no single "fixed" version exists to which copyright can attach. ${ }^{12}$ Or so a logical interpretation of fixation would dictate.

Yet, despite the possibility of a logical or literal interpretation of copyright's fixation requirement, fixation as applied is far from logical or literal. Instead, fixation serves to limit the scope of copyright protection for conceptual work. ${ }^{13}$ In

2011); and for a discussion on the idea/expression dichotomy, see Baker v. Selden, 101 U.S. 99 (1879), to which I return in my conclusion, infra.

6. M. Kramer Mfg. Co. v. Andrews, 783 F.2d 421, 432-33 (4th Cir. 1986).

7. 17 U.S.C. $\$ 101$ (emphasis added).

8. Douglas Lichtman, Copyright as a Rule of Evidence, 52 DUKE L.J. 683, 717 (2003).

9. Laura Heymann, How To Write a Life: Some Thoughts on Fixation and The Copyright/ Privacy Divide, 51 WM. \& MARY L. REV. 825, 829 (2009) ("Because many works of creative expression are fixed in some form, the subject of fixation arises in relatively few cases-typically in connection with computer technology, when the question is whether fixation in computer memory meets the statutory requirement.").

10. Gregory S. Donat, Note, Fixing Fixation: A Copyright with Teeth for Improvisational Performers, 97 Colum. L. Rev. 1363 (1997); Carrie Ryan Gallia, Note, To Fix or Not to Fix: Copyright's Fixation Requirement and the Rights of Theatrical Collaborators, 92 MINN. L. REv. 231, 240 (2007); Heymann, supra note 9, at 829.

11. Even then, what is protected is not the underlying improvisational work - what we might call the underlying or primary work - but the capturing of the work, the superficial or secondary work created merely to produce a record of the first. Trenton v. Infinity Broad. Corp., 865 F. Supp. 1416, 1425 (C.D. Cal. 1994) (finding that the live radio program, or primary work at issue, was not fixed, but the recording of it, that is, the secondary work, was fixed).

12. 1 Melville Nimmer \& David Nimmer, Nimmer on Copyright $\S 1.08[C][2]$ (live performance lies outside the scope of copyright protection).

13. Wendy Gordon, An Inquiry into the Merits of Copyright: The Challenges of Consistency, Consent, and Encouragement Theory, 41 STAN L. REV. 1343, 1383 (1989) ("[T]he fixation and marking 
so doing, it creates uncertainty as to when a work of art may fail to qualify as fixed. This is truest when the work is short-lived, or changing. Unfortunately, recent case law has added to the confusion. In Kelley v. Chicago, discussed in detail below, the Seventh Circuit Court of Appeals held that a large outdoor installation of landscape art failed to clear the fixation hurdle because it was "inherently changeable." 14 Though it offered multiple rationales for denying copyright protection to artist Chapman Kelley's landscape installation, it made clear that the garden could not be considered fixed because of the changes it underwent through exposure to insects, animals, and weather, all of which were not under the artist's control. ${ }^{15}$

This Essay will argue that copyright illogically excludes conceptual art from protection on the basis of fixation, given that well-settled case law has interpreted the fixation requirement to reach works that contain certain kinds of change so long as they are sufficiently repetitive to be deemed permanent. ${ }^{16}$ While conceptual art may perhaps be better left outside the scope of copyright protection on the basis of its failure to meet copyright's other requirements, this Essay concludes that fixation should not be the basis on which to exclude conceptual art from protection. There are of course both normative and descriptive questions around the copyrightability of conceptual art, and this Essay addresses itself primarily to the descriptive question of fixation, and whether works of art that contain change, by design, must be excluded. Just because a work may be what Kelley called "inherently changeable" does not mean that it need necessarily fail to qualify as fixed. ${ }^{17}$ This Essay explores the tension that the Kelley court identified between copyright law and certain works of contemporary art to argue that many kinds of art can be understood by analogy to well-settled case law-like Williams and its progenythat finds that some works may be fixed even when they contain change. By parsing a few kinds of change that occur in works of conceptual art, I hope to offer comfort to conceptual artists who would like to see their practices at least potentially protected by copyright, as well as guidance to courts seeking to apply or distinguish Kelley.

Part I surveys the rationales for the fixation requirement and discusses the case law holding that works of art that change may still qualify for protection, culminating in the puzzling decision to the contrary in Kelley. Part II offers a taxonomy of different kinds of conceptual art that could be seen as "inherently changeable," per Kelley, and argues that these categories should be understood and treated distinctly. Finally, this Essay concludes that Kelley's overly broad "inherently changeable" test threatens to exclude from copyright protection many different kinds of conceptual art on the basis that their changing or changeable

requirements and the limits on protectable intellectual products and copyright owners' rights function as boundaries in the same way as the edges on personal property or physical boundaries around realty do.").

14. It refused copyrightability on multiple grounds, including authorship and subject matter. See Kelley v. Chi. Park Dist., 635 F.3d 290, 304, 306 (7th Cir. 2011).

15. Id.

16. Williams Elecs., Inc. v. Artic Int'1, Inc., 685 F.2d 870, 874 (3d Cir. 1982).

17. Kelley, 635 F.3d at 304. 
nature renders them unfixed. Some of these works are analogous to the changing works that have been protected through copyright in spite of their internal change, like the video games in Williams, and some of them diverge in ways that might or might not be relevant for copyright law. I conclude that courts should be wary of relying on Kelley and should treat different kinds of conceptual art differently depending on what kind of art they are adjudicating.

\section{COPYRIGHT'S FIXATION REQUIREMENT AND WORKS THAT CHANGE}

\section{A. Copyright as a Legal ReQuirement}

Fixation has long been seen as a sine qua non of federal copyright. ${ }^{18}$ It used to be a rather literal-minded requirement; copyright arose in an era in which fixation involved actual physical media: an imprint on wood or paper, a pressing into a record, paint on canvas, and so forth. In the early digital era, courts struggled to apply the fixation requirement as something that could still limit the outer boundary of copyright protection while not insisting on physical requirements that were a strain to apply in some cases. Michael Madison has written very thoughtfully of the "dematerialization" problem of copyright law, describing tensions that arise when trying to apply forms of reasoning based on tangible forms to intangible or ephemeral works of art. ${ }^{19}$

That being said, the statute itself contemplates less than perfect stability in its fixation requirement. As stated in 17 U.S.C. § 101, “[a] work is 'fixed' in a tangible medium of expression when its embodiment in a copy or phonorecord, by or under the authority of the author, is sufficiently permanent or stable to permit it to be perceived, reproduced, or otherwise communicated for a period of more than transitory duration." The statute expressly inserts a standard: "sufficiently permanent or stable to permit it to be perceived . . . for . . . more than transitory duration" so as to limit the exclusionary force of the fixation requirement. As might be expected, case law has relied on this standard to find some works that feature changes to have been fixed because, though they are not permanent or fixed per se, they are "sufficiently permanent" to be considered "more than transitory.". 20

Perhaps unsurprisingly then, the fixation requirement has been interpreted flexibly, with full weight given to the wiggle room created by the statute's standard: "sufficiently permanent or stable." A work can qualify as fixed so long as it is created in a medium "capable of identification and having a more or less

18. "The two elements most essential in establishing the existence of a copyright are: (1) a work of authorship; and (2) fixation, i.e., fixed in a tangible medium of expression." Prod. Contractors, Inc. v. WGN Cont'l Broad. Co., 622 F.Supp. 1500, 1502 (D.C. Ill. 1985).

19. See generally, Michael Madison, Beyond Creativity: Copyright as Knowledge Law, 12 VAND. J. Ent. \& Tech. L. 817, 846 (2010); Michael Madison, The End of the Work As We Know It, 19 J. INTELL. PROP. L. 325, 326 (2012).

20. Williams Elecs., 685 F.2d at 874; Microstar v. Formgen, 154 F.3d 1107, 1111-12 (9th Cir. 1998). 
permanent endurance." 21 Indeed, a copyrighted work need not last long at all, so long as it has been fixed at some point. ${ }^{22}$ Crucially, "fixation does not imply permanence." 23

The fixation requirement arose after the abandonment of the publication requirement in copyright law and the subsequent establishment of fixation in a tangible medium as an element of copyrightability. ${ }^{24}$ There have been many rationales advanced for the ongoing necessity of the fixation requirement. Laura Heymann argues that the language of the statute suggests that the first purpose of the fixation requirement lies in the use and enjoyment of the work by others: "The explanation that a work is fixed only if it can be 'perceived, reproduced, or otherwise communicated for a period of more than transitory duration' suggests a concern not with enjoyment of a work by its audience (as would be true with an improvisational performance) but with some degree of permanence that allows future use of the work." 25 Second, she stresses that the work signals authorship, by requiring that a work be fixed "by or under the authority of the author"; the emphasis on the person who fixes the work suggests something important about "the concept of authority." ${ }^{26}$ She also stresses, perhaps paradoxically, that in the era of the Internet, content can be made "more permanent and more unstable," and the fixation requirement takes on added importance in policing the boundary between public and private. ${ }^{27}$ Fixation, for better or for worse, has the effect of reifying a work. ${ }^{28}$ Douglas Lichtman finds that the strongest justification for the fixation requirement is evidentiary. ${ }^{29}$ By drawing a parallel between the publication, notice, and deposit requirements under the 1909 Copyright Act and the fixation requirement that replaced them in the 1976 Act, he argues that the best of the candidate rationales for the fixation requirement is evidentiary in nature. ${ }^{30}$ Even then, however, the fixation requirement cannot be fully explained or justified on those grounds since, as he points out, that a work need only have been fixed briefly and not permanently means that it might not be around for the purposes of serving as evidence during litigation. ${ }^{31}$

21. NiMMER, supra note 12 , at $\$ 1.08[C][2]$ (emphasis added).

22. Lichtman, supra note 8, at 716 ("The most striking aspect of the fixation requirement is that an acceptable tangible embodiment does not need to survive for any significant period of time.").

23. Id. at 717 .

24. Under the Copyright Act of 1909, "publication" of the work was typically required to trigger copyright protection, and in a number of ways, the publication requirement effectively built in a fixation requirement. Lichtman, supra note 8, at 719-20.

25. Heymann, supra note 9 , at 842 (internal citations omitted).

26. Id.

27. Id. at 870 .

28. Id. at 843 .

29. Lichtman, supra note 8 , at 718,730 .

30. Id.

31. Id. at $732-33$. 


\section{B. FiXATION AS APPLIED}

Williams v. Artic International is an important jurisprudential starting point for considering how courts have adapted the fixation requirement for works that contain changes. ${ }^{32}$ In Williams, the plaintiff was a video game manufacturer selling the popular game, DEFENDER, and defendant was a competitor selling electronic components and circuit board "kits" that contained a game virtually identical to DEFENDER, called DEFENSE COMMAND. ${ }^{33}$ Williams had registered three copyrightable works relating to DEFENDER: one in the program; one for the audiovisual effects displayed during the game's "attract mode," which played the same sequence in a loop; and one for the audiovisual effects displayed during "play mode." ${ }^{34}$ There had been a recent flurry of cases debating the extent of copyrightability in video games, and Williams built on and extended those by holding that the video game's display was an original audiovisual work that qualified as "sufficiently permanent or stable" for purposes of the fixation requirement. ${ }^{35}$ First, the court rejected the defendant's argument that the audiovisual displays could not be copyrighted for lack of fixation, on the grounds that "the original audiovisual features of the DEFENDER game repeat themselves over and over." ${ }^{36}$ Citing multiple cases in support, it held that audiovisual workseven ones that change - may satisfy copyright's fixation requirement "whenever the work is 'sufficiently permanent or stable to permit it to be . . reproduced, or otherwise communicated' for more than a transitory period." 37 Williams held that the "images in plaintiff's audio visual game could be said to be 'fixed' in view of the fact that 'new' images generated or created by the video game each time attract mode or play mode was displayed were identical or substantially identical to the earlier ones." 38 Next, the court rejected the idea that players' participation affected the copyright: "the player's participation [does not] withdraw[] the game ... from copyright eligibility" for lacking a "set or fixed performance." ${ }^{39}$ Nor was the player to be considered a co-author, it held, because "[a]lthough there is player interaction with the machine during the play mode which causes the audiovisual presentation to change in some respects from one game to the next in response to the player's varying participation, there is always a repetitive sequence of a substantial portion of the sights and sounds of the game, and many aspects of the display remain constant from game to game regardless of how the player operates the controls." ${ }^{40}$ Williams built on Stern Electronics, Inc. v. Kaufman, which had likewise confronted the question of copyrightability in the audiovisual aspects of a

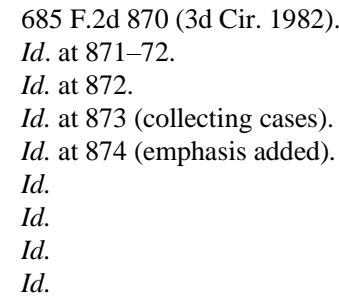


video game. ${ }^{41}$ Stern offered a more detailed explanation of how a user of the video game might experience it in various ways, before concluding that the variations did not threaten the work's fixation for copyright purposes:

No doubt the entire sequence of all the sights and sounds of the game are different each time the game is played, depending upon the route and speed the player selects for his spaceship and the timing and accuracy of his release of his craft's bombs and lasers. Nevertheless, many aspects of the sights and sequence of their appearance remain constant during each play of the game. These include the appearance (shape, color, and size) of the player's spaceship, the enemy craft, the ground missile bases and fuel depots, and the terrain over which (and beneath which) the player's ship flies, as well as the sequence in which the missile bases, fuel depots, and terrain appears. Also constant are the sounds heard whenever the player successfully destroys an enemy craft or installation or fails to avoid an enemy missile or laser. It is true . . that some of these sights and sounds will not be seen and heard during each play of the game in the event that the player's spaceship is destroyed before the entire course is traversed. But the images remain fixed, capable of being seen and heard each time a player succeeds in keeping his spaceship aloft long enough to permit the appearances of all the images and sounds of a complete play of the game. The repetitive sequence of a substantial portion of the sights and sounds of the game qualifies for copyright protection as an audiovisual work. ${ }^{42}$

Stern helpfully articulates a range of possible changes within or different experiences of the work to clarify that some subset of possible variations will not have the effect of "unfixing" a work for the purposes of copyright protection.

Williams, building on Stern and other early video game cases, has been entrenched in the three decades since it was handed down, and it offers a helpful approach to determining fixation in some kinds of conceptual art. ${ }^{43}$ It could be that it is most apposite as applied to cases in which the question of fixation arises as part of the defense, since a finding of no fixation in that context will mean defendant has not infringed a valid copyright. This posture may induce judges to be more generous in finding a work's having been fixed if finding differently might mean allowing otherwise objectionable conduct by the defendant to go unpunished.

In light of Williams, it is somewhat puzzling to reconcile Kelley v. Chicago Park District, which held that an artistically designed garden could not be considered copyrightable, in part because it was "inherently changing" and thus unfixed. ${ }^{44}$ Kelley arose in a very different posture from Williams, which offers the beginning of a reconciliation of the two cases. Still, the procedural difference between them does not go far enough to explain the divergence in their legal analyses of fixation. Chapman Kelley is a nationally-renowned installation artist, a painter who at a certain point in his career began to work with wildflowers instead of canvasses.

41. 669 F.2d 852 (1982).

42. Id. at 856 .

43. A February 2016 Westlaw search showed that Williams has been cited 689 times since it was handed down, seventy-eight of which citations are in case law, of which seventy-seven are approving citations.

44. 635 F.3d 290 (7th Cir. 2011). 
Pursuant to a contract he formed with the Chicago Park District in 1984, he designed and installed a large-scale urban landscape work called Wildflower Works in Chicago's Grant Park (pictured below).
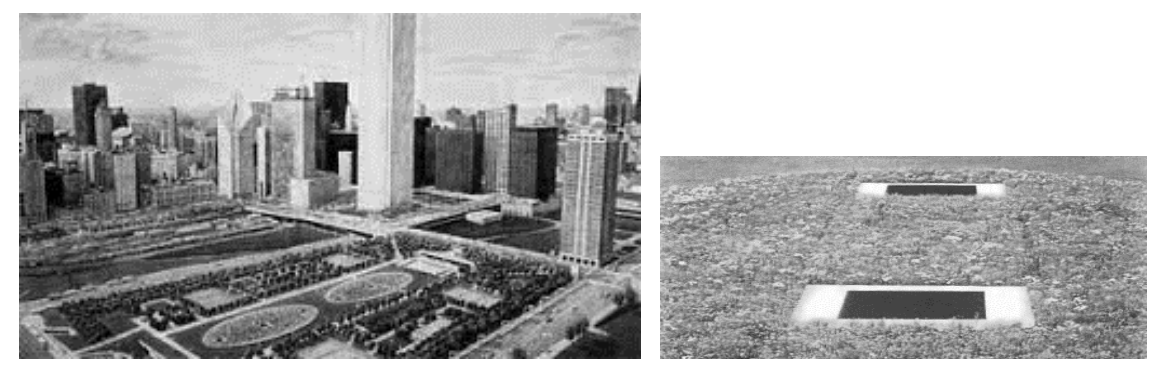

Kelley and his team planted several hundred thousand seedlings to maximize particular blooms at particular points during the year. That is, the team designed the garden in anticipation of how nature would unfold, seasonally, to continue to create a work of art that was pleasing, and evolved, over time. Kelley and a team of volunteers then tended to the garden, pruning it and otherwise caring for it. ${ }^{45}$ However, by 2004, the garden had deteriorated somewhat and the city decided that it wanted to put Grant Park to another use. ${ }^{46}$ The Park District made substantial changes to Wildflower Works, and Kelley responded by suing the Park District under the Visual Artists Rights Act of 1990 ("VARA"), among other claims, including breach of contract. After a bench trial, the district court held that although Wildflower Works could be a painting or a sculpture under VARA, it lacked the minimum originality copyright requires. ${ }^{47}$ On these grounds, the court rejected Kelley's moral rights claims because qualifying for VARA would require originality. It also argued that site-specific art is excluded from VARA protection. ${ }^{48}$ Finally, it held for Kelley on the breach claim but awarded only nominal damages of $\$ 1$, prompting both sides to appeal. ${ }^{49}$ The Seventh Circuit Court of Appeals affirmed in part and reversed in part, questioning the lower court's judgment as to the work's status as a painting or sculpture; its lack of originality; and its sweeping statement that all site-specific art is excluded from VARA. It thus affirmed the dismissal of Kelley's copyright claim on different grounds, but reversed the contract claim, finding for the Park District. In justifying its holding, the court took pains to distance itself from the lower court's reasoning, and to articulate its own rationales, citing Wildflower Works's lack of an author, lack of fixation, and failure to qualify as proper copyrightable subject matter. ${ }^{50}$

45. Id. at 291 .

46. Id.

47. Id. at 292 .

48. Id. at 292 (The court held for Kelley on the contract claim he brought, but awarded only nominal damages of $\$ 1$, leading to an appeal by both parties.).

49. Id.

50. Id. 


\section{THE IMPLICATIONS OF KELLEY}

In particular, Kelley took the opportunity to weigh in on the fixation requirement in expansive and uncertain language that caused many of us to wonder how far it might reach, and whether - and if so how - it was altering the settled case law with respect to fixation for works that are subject to certain sorts of change. For instance, it declared, rather without needing to opine on it, that "the law must have some limits; not all conceptual art may be copyrighted." ${ }^{1}$ Kelley appeared to be introducing a new test focusing on the essence, or essential qualities of the work, which held that a work that was "inherently changing"- that is, whose essence was dynamic change - should not be considered fixed for copyright law.

By supporting its ruling as it did, Kelley appears to have created a subcategory of works, ones that are "inherently changing." This category is too broad to be helpful. It does not distinguish between changes to a work made intentionally or accidentally, nor does it isolate who made the changes, what kinds of changes they were, and perhaps most importantly, whether these were, in some sense, reasonably foreseeable because they were the point of the work. By deemphasizing the functional aspects to change within a work, that is, why those changes are there and what purposes they serve, Kelley unwisely places artificial emphasis on the work's ontological status: what is the "essence" of the work? This is odd, given that it pays only passing attention to what is, in my view, the true ontological question: whether a garden is, as a thing, properly the subject of copyright protection. By relying on unstable and unverifiable reasoning having to do with the "essence" of a thing, Kelley opened the door to subsequent courts misusing its "inherently changing" test to dodge the subject matter question altogether.

In Kim Seng Company v. J \&A Importers, Inc., the court adopted Kelley in just this way. ${ }^{52}$ It held that a photograph of a bowl of Vietnamese food was not protectable because of the scènes à faire doctrine: giving Kim Seng a copyright "might give Kim Seng a monopoly over using such photographs on food packages." ${ }^{3} 3$ But it also addressed the food itself as a food sculpture and decided that "because food is perishable, it cannot be considered 'fixed' for copyright purposes." 54 Kim Seng cited Kelley, and reasoned that "[1]ike a garden, which is 'inherently changeable,' a bowl of perishable food will, by its terms, ultimately perish. Indeed, if the fact that the Wildflower Works garden reviving itself each year was not sufficient to establish its fixed nature, a bowl of food which, once it spoils is gone forever, cannot be considered 'fixed' for the purposes of Sec. 101." 55 As the earlier discussion of the fixation requirement makes plain, Kim Seng gets this part of copyright law wrong: the fixation requirement does not require permanence, or even that a fixed work last very long. ${ }^{56}$ It merely requires fixation

51. Id. at 304 .

52. 810 F.Supp.2d 1046 (C.D. Cal. 2011).

53. Id. at 1057.

54. Id. at 1054 (emphasis added).

55. Id.

56. Lichtman, supra note 8, at 716. 
for some non-transitory period. The work in Kim Seng can be distinguished from the garden in Kelley because one was merely going to rot, over time, while the other was going to evolve; recall that Kelley and his team purposely planted seeds that would create change across the seasons. This case shows that Kelley's "inherently changing test" can be applied broadly, and I think, improperly given a basic understanding of the operation of the fixation requirement. A better route for Kim Seng would have been to hold that the bowl of noodles was not protectable as a useful article; calling it a food sculpture to begin with seems like creative lawyering, to put it generously. That highlights why Kelley's inherently changing test creates confusion and invites unstable reasoning, since it was true in Kelley, too, that emphasis on copyrightable subject matter could have provided a clearer doctrinal ground for refusing copyright protection. Rather than emphasizing fixation, Kelley might have held fast to the idea that it expressed at one point in the opinion, that "simply put, gardens are planted and cultivated, not authored," and therefore are not the subject matter of copyright." fixation into the mix, it would have done less to create uncertainty around the scope of Williams, and it would have more properly, in my view, policed the proper scope of copyright's subject matter.

Worse still, Kelley's new test for fixation potentially sweeps up into its ambit all works that contain change because of the term "inherent." In so doing, Kelley may stand in tension with well-settled case law that has held that some sorts of changes do not threaten a work's fixation status. In that sense, Kelley is not just unhelpful, it is wrongheaded. By lumping together potentially all works that contain "inherent change," it overlooks the fact that well-settled case law suggests that some sorts of changes will not threaten a work's fixation.

Lastly, it may be that Kelley stands in tension with current artistic practices, known broadly as conceptual art. Because the court here held that a work of art would not be fixed if it changes unpredictably with forces beyond the author's control, and acknowledged the toll taken by such elements as weather, insects, rabbits, and so forth, the question arises as to whether other sorts of forces beyond the author's control might similarly threaten the work's status as fixed. Under the "inherently changing" test, conceptual forms of art, such as viewer-participatory art, or works that incorporate "random changes" like the ones discussed in Kelley, might be vulnerable to being deemed unfixed. This is a problem from the perspective that copyright typically aims to promote progress and incentivize the creation of new works. ${ }^{58}$ Further, a fundamental tenet of copyright law is that courts should not distinguish among kinds of work to privilege some over others with respect to the existence of copyright protection. ${ }^{59}$

The past decade has been one in which the art world has witnessed increasing viewer participation. Generally, the past decade has seen a well-documented flourishing of artistic creation in connection with new digital tools that make

57. Kelley, 635 F.3d at 304.

58. Fogerty v. Fantasy, Inc., 510 U.S. 517, 524 (1994).

59. Bleistein v. Donaldson Lithographing Co., 188 U.S. 239, 251 (1903). 
creativity among the everyday population more visible and easier to disseminate. This is not to say that audience participation is a new thing of course, but it is newly part of the visual art world's institutional manifesto. One might speculate that the art world has had to respond to declines in state funding, which have necessitated a broader base funding strategy and thus effectively popularized elite art institutions. One could further speculate that invitations to audiences to participate in works of art are an expression of art's democratization; along these lines, parents are bringing children to museums more than they used to, and so forth.

\section{THE PROLIFERATION OF CONCEPTUAL ART}

Once upon a time, conceptual or modern art was considered shocking and existed on the fringe of the mainstream, perhaps celebrated by elites but not exactly embraced by the general population. In 2016, it would seem as though conceptual art has left the alternative sphere and finally joined the mainstream. Indeed, in the words of one arts commentator:

The great surrealist Marcel Duchamp made pieces that required participation from viewers. So did Andy Warhol. Those were rare events in a world where simply beholding an object had been the norm for thousands of years.

These days, things are increasingly about making audiences part of the action. You can hardly enter a gallery without some demand that you make the art work yourself, by stepping or scribbling on it, by dancing or singing with it, turning its crank, eating it or tapping a keyboard. ${ }^{60}$

Yet conceptual art with its insistence on various elements including viewer participation, evolution through time, and natural or living materials seems orthogonal to copyright law, and especially so after Kelley, for the reasons explained above. ${ }^{61}$ It is possible that copyright law deliberately excludes conceptual art from the scope of protection as a sui generis area, withholding protection of which is justified on policy grounds. But no legal authority exists to support that notion. Instead, excluding conceptual art is the logical consequence of other doctrines-fixation, which is the focus of this Essay, and the idea/expression dichotomy, which is discussed briefly in the Conclusion. If the fixation requirement is the main barrier to copyright law's excluding conceptual art from

60. Ray Mark Rinaldi, Art and the active audience: Participatory art changes audience role from viewer to doer, THE DENVER POST (Dec. 31, 2012, 2:25 PM), http://www.denverpost.com/ci_22288730/ art-and-active-audience-participatory-art-changes-audience [https://perma.cc/467X-ZK88].

61. Charles Cronin, Dead on the Vine: Living and Conceptual Art and VARA, 12 VAND. J. ENT. \& TECH. L. 209, 213-14 (2010) ("Along with this general trend has come the expansion of media in which artists render their work, which now include living — and once living — objects like plants, animals, and other relatively ephemeral organic materials. These developments in the visual arts, which have mainly occurred within the past fifty years, have led to artistic endeavors that U.S. copyright law does not comfortably accommodate - even though copyright law ostensibly fosters and protects the results of such creative enterprise. This remains true despite amendments to the Copyright Act enacted as recently as 1990 that expanded protection for works of visual art and architecture.") (internal citations omitted). 
the ambit of its protection, then it is worth puzzling through whether the rationales underpinning the fixation requirement, and the case law applying it, align with current practices in conceptual art.

There are at least three types of conceptual art that could be considered "inherently changing" under a straightforward understanding of those words: first, art that changes but does so in repetitive or predictable patterns, perhaps regularly returning to its original state and "starting over"; second, art that evolves from one thing, or state, to another, without reverting to its original or necessarily repeating itself; and third, art that is intended —or allowed - to deteriorate or decay. ${ }^{62}$ This third kind may include art not intended to last for very long, that is, ephemeral or transitory art, as well as art designed to decay more slowly over time. These three kinds - repetitively changing, evolving, and deteriorating art-require courts to apply diverse legal authorities and analytical strategies.

Key to all three of the categories of conceptual art to be discussed is that not only do they contain some change, they thematize it. That is, they center on the experience of change in some way that is crucial to the works' reception and meaning. The taxonomy underscores that Kelley's "inherently changing" test obscures legally relevant differences among types of conceptual art that deliberately and foreseeably contain change.

\section{A. Repetitively-Changing Conceptual ART}

Olafur Eliassons's The Weather Project (2003) is an example of this kind of work that changes. It features representations of the sun and the sky, contained within the Turbine Hall in the Tate Modern in London. ${ }^{63}$

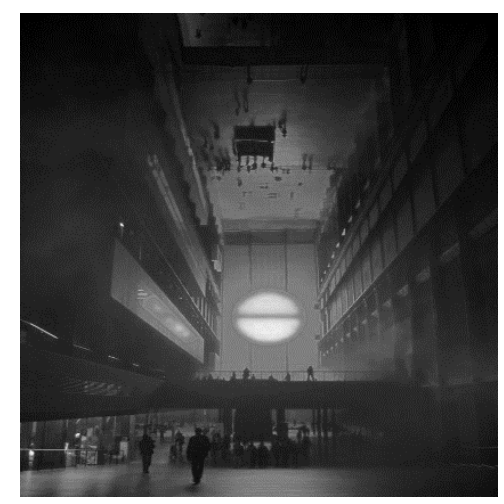

Eliasson uses monofrequency lights, projection foil, haze machines, mirror foil,

62. This list is not of course exhaustive; it is an attempt to taxonomize kinds of art in ways that can be translated meaningfully into jurisprudential solutions.

63. Olafur Eliasson, The Weather Project, TATE, http://www.tate.org.uk/whats-on/exhibition/ unilever-series-olafur-eliasson-weather-project/olafur-eliasson-weather-project [https://perma.cc/5USZDPJR] (last visited Feb. 12, 2016). 
and aluminum to create a fine mist made of sugar and water that occupies the space and points to the artificial division between inside and outside. The work changes in connection with natural forces beyond the artist's control, such as light and air quality, but it changes in ways that are predictable, and repetitive. There is a range, in other words, of values creating colors between light and dark, and the atmosphere grows more and less hazy throughout the day as the interior mist and fog gathers into cloud-like formations. ${ }^{64}$ The mirrored ceiling reflects visitors below and creates a kind of optical illusion whereby the ceiling appears to have disappeared, leaving only a reflection of the ground below, refracting orange misty light. ${ }^{65}$ The viewers become participants in the work by casting shadows and moving their limbs to observe their own reflections in the ceiling above, and of course their participation in number changes the amount and quality of light in the room. Viewers were captivated by this ability to cast shadows, see themselves, and affect the work of art. One art critic described viewers of The Weather Project as "intoxicated with their own narcissism as they ponder themselves elevated into the sky." "66 Some two million visitors came to the space during the six months of its exhibition, many more than once. ${ }^{67}$ The Weather Project could be said to change, as light changes throughout the day, and as visitors participate in the work's contours and experience.

Yet would, under Kelley, the work be considered "inherently changing" for the purposes of being denied copyright protection on the grounds that it lacked fixation? It seems to me that it probably would (descriptively) but that it probably should not be (normatively). This is because the parameters of the work of art are set by the author, and both the viewer's changes through participation and the light and atmospheric changes create some but predictable alterations with a predictable set of possible experiences. Per Williams, when a work's changes occur within a framework that repeats "over and over," it may qualify as "sufficiently permanent or stable" to be deemed fixed. ${ }^{68}$

A second example is an installation by Felix Gonzalez-Torres, in a work of art dedicated to his lover, Ross Laycock, who died of AIDS in 1991.69 The work, "Untitled" (Portrait of Ross in L.A.) (1991), featured 175 pounds of candies piled on the floor of the museum.

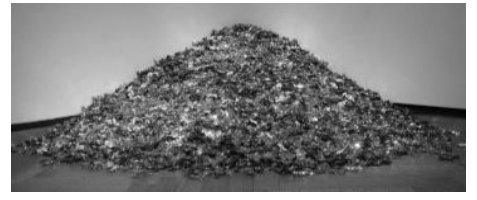

64. Id.

65. Id.

66. Mark Godfrey and Rosie Bennett, Public Spectacle: An interview with Brian O'Doherty, 80 FRIEZE: CONTEMPORARY ART AND CULTURE 56 (Jan./Feb. 2004), http://www.frieze.com/issue/article/ public_spectacle/ [https://perma.cc/F6AC-JWLA].

67. Id.

68. Williams Elecs., Inc. v. Artic Int'1, Inc., 685 F.2d 870, 873-74 (3d Cir. 1982).

69. About This Artwork: Felix Gonzalez-Torres, American, born Cuba, 1957-1996, "Untitled" (Portrait of Ross in L.A.), 1991, ART INSTITUTE CHICAGO, http://www.artic.edu/aic/collections/artwork/ 152961 (last visited Feb. 12, 2016). 
The 175 pounds represented the ideal weight of Gonzalez-Torres's lover, who lost weight as a side effect of AIDS, wasting away as his sickness intensified. Viewers may experience the work as changing, depending on when they see the work and whether they accept the author's invitation to take a piece of candy when they visit. By making small changes to it, viewers cumulatively have the power to change the work considerably. By participating in the removal of candies, the viewer was symbolically involved in the weight loss and illness of Ross. The work of art changed throughout the day, and could be very full of candy or quite bare, conveying different impressions to viewers. At the start of the day, the work might convey hopeful plenitude, or possibility; at the end, perhaps it might convey emptiness, absence, a full thing ravaged by time. The replenishing of candies daily was an act of symbolism suggesting Ross could be granted perpetual life through art. Hence the change to the work was thematic and necessary to the very point of the art.

In terms of copyright law's analysis, the change existed within certain fixed parameters like the parameters described in Stern such that "many aspects of the sights and the sequence of their appearance remain constant during each [experience] of the [work]."70 Interestingly, the lower court in Kelley made reference to this very work. As the district court reasoned: "Although arguably no two viewers of 'Untitled (Portrait of Ross in L.A.)' see the same work, there is no argument that its mutability precludes it from being described as a work of art."71 Consequently, in spite of the way the work changes throughout the day, applying the logic of Williams justifies adopting the legal fiction of "sufficient permanence" because the work's changes, while real, repeat "over and over" in similar patterns.

Another way to frame this might be to state that although this work is one in which an artist invites viewer participation that could change the work significantly, thus potentially rendering the work vulnerable to Kelley's “inherently changing" lack of fixation theory, the work does so within parameters that create a scope of foreseeability around the work's starting and ending points. The viewer can only change the work "so much." That the viewer's input has a limited, and predictable, impact on the work constrains the range of possible different versions of the work, and renders it effectively fixed. Repetitively-changing conceptual art deserves to benefit from the same treatment the video games receive under Stern, Williams, and their progeny. These kinds of works clear copyright's fixation hurdle.

\section{B. Evolving Conceptual Art}

A second category of conceptual art work that challenges copyright's fixation jurisprudence is the work that changes over time, ultimately becoming something new or different. Unlike in Williams, and in Gonzalez-Torres's tribute to Ross with

70. Stern, 669 F.2d 852, 856.

71. Kelley v. Chi. Park Dist., No. 04-C-07715, 2008 WL 4449886, at *4 (N.D. Ill. Sept. 29, 2008). 
candy, the work does not reset and begin again. Recall the court's emphasis, in Williams, on the way the "audiovisual features of the DEFENDER game repeat themselves over and over."72 Though they were not fixed, it was as though they were fixed; their repetition is what met the statute's "sufficiently permanent standard." $" 73$

Consider for an example of this second kind of work, The Obliteration Room (2011), by distinguished Japanese visual artist Yayoi Kusama. This work of art consists of a room in a prefab house installed in the Queensland Gallery of Modern Art in Australia. ${ }^{74}$ The room starts out pure white, with all of its surfaces and pieces of furniture hospital white. Over the course of two weeks, the work invites viewers in, allowing children to help themselves to brightly colored round stickers they can apply anywhere they like. The stickers, thousands and thousands of them, were applied, as far as I can tell, only by children. ${ }^{75}$

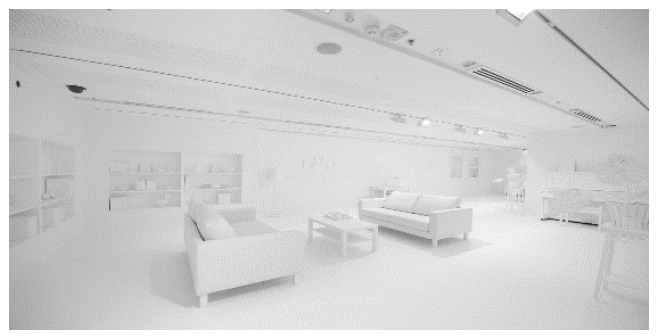

Over time, the room got brighter, more energetic, more colorful, and messier. The idea was for the white walls to transform eventually into what the exhibiting gallery calls "an unrecognizable blur of color."76

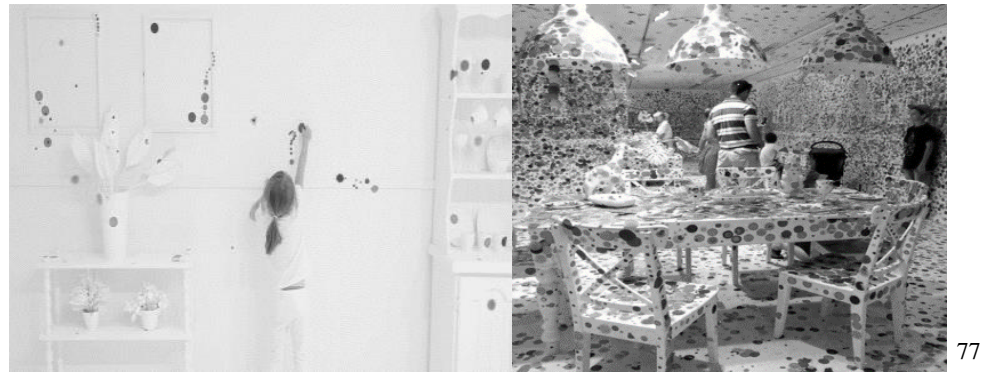

72. Williams, 685 F.2d at 874

73. 17 U.S.C. $\$ 101(2012)$.

74. Christopher Jobson, This is What Happens When You Give Thousands of Stickers to Thousands of Kids, COLOSSAL (Jan. 1, 2012), http://www.thisiscolossal.com/2012/01/yayoi-kusamaobiliteration-room/ [https://perma.cc/97MD-W644].

75. To view a young girl applying some stickers, see Yayoi Kusama brings colorful dot-covered obliteration room to New York, DESIGNBOOM (May 26, 2015), http://www.designboom.com/art/ yayoi-kusama-david-zwirner-obliteration-room-new-york-05-26-2015/ [https://perma.cc/HA8U-FX9U].

76. Id.

77. This is a view from the outside of the installation, which is created using a prefab house. 
This is a room that arguably started as one thing - a white room. It ended as another - a brightly colored room. Ontologically, sure - they are both rooms. But the impressions they convey and their aesthetic qualities are quite different. The room never goes back to being white, that is, the stickers are not regularly removed to "reset" the work the way the candies are replenished in Gonzalez-Torres's candy memorial. Nor is the room vacillating between light and dark, but it is essentially the same thing, like Eliasson's The Weather Project. Thus one might reasonably ask when the work is finished (as a question of art) or fixed (as a question of copyright law).

Conceptual art that evolves from one thing to another might be said to present a harder question for copyright law, from the perspective of fixation. One way courts might deal with these works, since they would not quite as clearly fall under Williams, would be for courts to adopt a reasonable foreseeability standard. At the time when the work is presented to the public, or when the non-authorial change to the work could be said to begin (say, by offering colored stickers to the public), it is reasonably foreseeable that the outcome of the work, when its exhibition ceases, would look something like this. Of course it is to some extent indeterminate; in different cities or seasons different people might use different stickers and in different concentrations, etc. But the evolution to a different version of the workperhaps a very different version-can largely be foreseen. Because of that foreseeability, the fixation requirement should not be understood to cut off copyright protection on the basis of the work's changing nature.

A final example makes plain that in some cases, the finished work might be a kind of canvas inviting further work to be added; both "versions" might well be considered fixed even though they might differ. In Seattle, where I live, there is a legendary wall on which visitors are invited to place a piece of their chewing gum. Over years, it grew more colorful, busier and bigger (as its original space grew too small to accommodate the growing number of pieces).
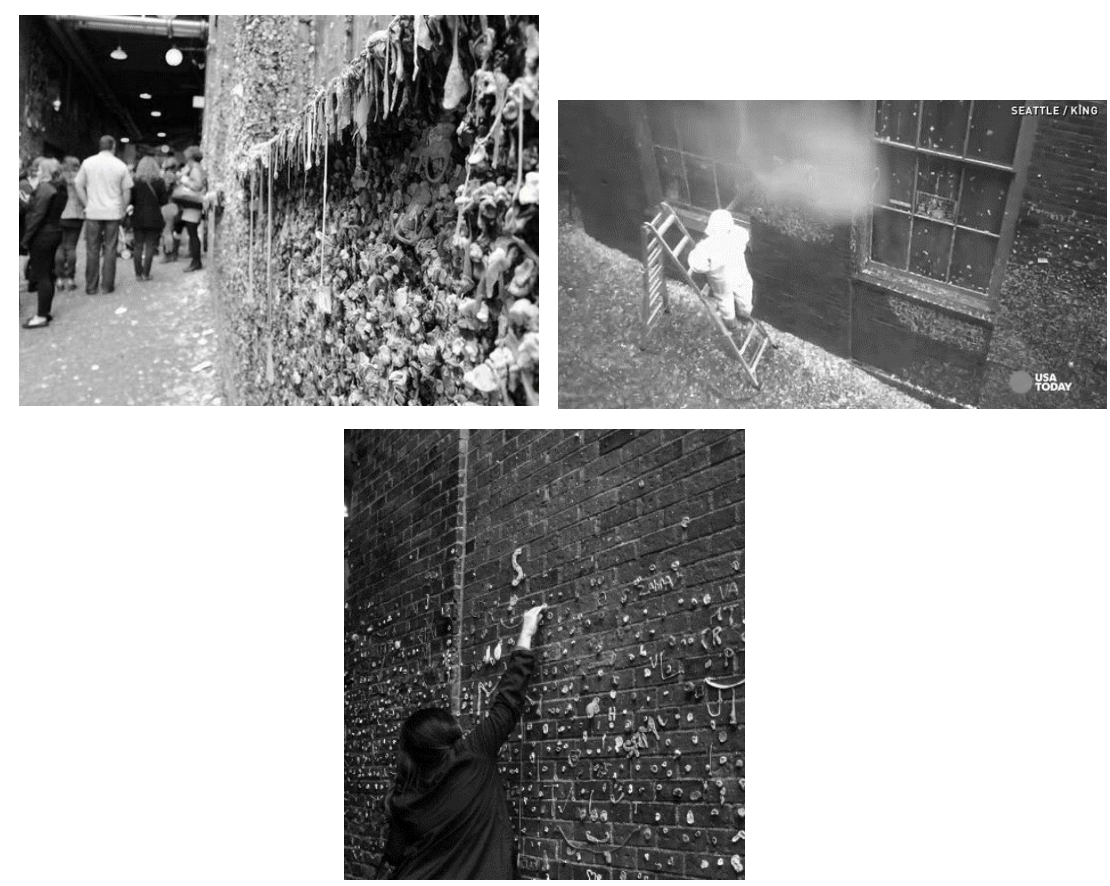
Had the original wall been a canvas or work set up by an artist targeting viewerparticipation, we might have analogized it to a work of art that foreseeably could expect to grow beyond its original boundaries as viewers continued to add pieces of gum. Recently, the wall was cleaned for the first time in twenty years, scrubbed free of some 2,350 pounds of gum. ${ }^{78}$ Within the first three or four days after the cleaning was complete, the wall began to be decorated in gum again, with a flash mob organizing a demonstration in support of victims of terrorist attacks in Paris. ${ }^{79}$ In short, whatever it began as - a mere brick wall in an alley - the Gum Wall has become a form of urban art that is now foreseeably going to be turned into a form of performance art through spontaneous viewer chewing-gum placement. While the specific expression of the gum on the wall cannot be entirely predicted, it is reasonably foreseeable within a range of possible outcomes. The analogy is, of course, strained, since the wall began as a wall, not a canvas or other authordirected work. But it helps to illuminate the role that viewer participation can play in taking a work from a starting place to an ending place (or simply to another place), and how that might create a question for copyright law's fixation requirement. Relying, as I suggest, on foreseeability analysis, would not eliminate problems: it is hardly as though foreseeability is a model of clarity in tort law where it wields such doctrinal power. ${ }^{80}$ Yet it could help copyright law align with the intentions of the author, which might be precisely to unleash on her work the forces of the audience as a means of building a work around the theme of the viewer, or change, or the dynamic nature of artistic reception. ${ }^{81}$

\section{Deteriorating Conceptual ART}

A third category of conceptual art is one in which the work of art is designed to last only briefly - perhaps it is made of ice, or some other temporary-to-the-context substance - or it is designed, in fact, to deteriorate. The British sculptor and environmental artist Andy Goldsworthy comes to mind. ${ }^{82}$

Here he is working with delicate branches balanced on each other and susceptible to destruction as soon as a heavy wind arrives, and to the right, having

78. Seattle's gum wall cleaned for first time in 20 years, USA TODAY (Nov. 17, 2015), http:// www.usatoday.com/story/news/nation-now/2015/11/17/seattle-gum-wall-cleaned-first-time-20-years/ 75915168/ [https://perma.cc/G9DX-NSBR].

79. Lauren Frohne, "Re-gumming” the gum wall-for Paris, THE SEATTLE TIMES (Nov. 15, 2015, 12:16 AM), http://www.seattletimes.com/photo-video/video/re-gumming-the-gum-wall-withsupport-for-paris/ [https://perma.cc/2FR5-RMCB].

80. W. Jonathan Cardi, Purging Foreseeability: The New Vision of Duty and Judicial Power in the Proposed Restatement (Third) of Torts, 58 VAND. L. REV. 739, 740 (2005) (referring to foreseeability as "a scourge, and its role in negligence cases is a vexing, crisscrossed morass").

81. Such a thought experiment is not an absurd proposition. See also Shyam Balganesh, Foreseeability and Copyright Incentives, 122 HARV. L. REV. 1569, 1609 (2009) (carefully imagining foreseeability in the context of copyright's infringement analysis and reviewing costs and benefits of doing so).

82. Sculptor Turns Rain, Ice and Trees Into 'Ephemeral Works, ' NPR FRESH AIR (Oct. 9, 2015, 12:07 PM), http://www.npr.org/2015/10/08/446731282/sculptor-turns-rain-ice-and-trees-intoephemeral-works [https://perma.cc/2MFN-3WS7]. 
photographed an ice sculpture.
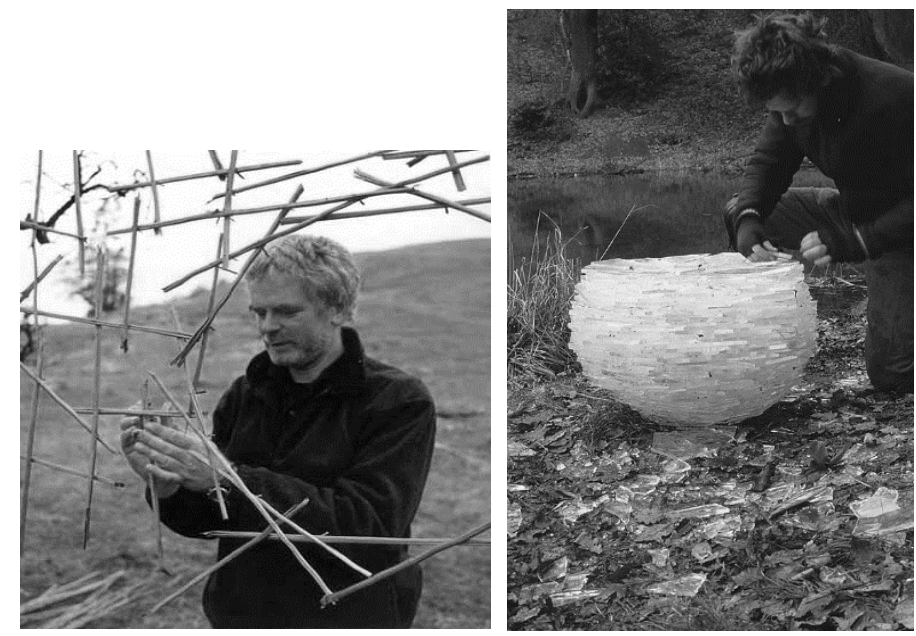

At what point is the work fixed? Is it when he stops composing the scene, and shifts to documenting/photographing it? The work's fragility, its vulnerability to decay or undoing, is what amplifies the beauty of the work. Indeed, it is the very point of his exquisite, careful craftsmanship. It seems senseless to argue that the things that will eventually undo it make it not count for copyright protection. Analogously, in the digital realm, courts debated whether seconds, or minutes, might be considered insufficiently transitory to count as fixed. ${ }^{83}$ These works of art are clearly present in a sort of finished state for seconds, or minutes, or hours, and maybe even days before undergoing major change. Yet because the works are susceptible to, that is, potentially changeable by, forces of nature, copyright seems to exclude them from protection. At least, this is copyright's attitude towards conceptual art as expressed in Kelley. Recall that in Kelley, the court emphasized that it was forces of nature-insects, winds, rabbits - that would alter the work, thus rendering it unfixed by the artist.

A final example of deteriorating art lies in a poem composed by William Gibson, the famous science fiction writer, author of Neuromancer. ${ }^{84}$ William Gibson's "Agrippa" was a poem that doubled as an unusually poignant publicity stunt. "Agrippa" was a poem sold to purchasers in a very limited edition in the form of a physical book containing a diskette to be played on a 1992-era Mac. Once playing, the work scrolled, unstoppably once, through the poem's 305 lines, and then was encrypted in the disk and never again accessible. That is, it disappeared. Indeed, when Gibson first read it, he reportedly introduced it with the

83. See. e.g., Cartoon Networks LP, v. CSC Holdings, Inc., 536 F.3d 121 (2d Cir. 2008).

84. William Gibson, Agrippa (A Book of the Dead), William GIBSON BOOKS, http:// www.williamgibsonbooks.com/source/agrippa.asp [https://perma.cc/Y4VA-UZVA] (last visited Feb. 12, 2016). 
following playful warning: “OK, sit down and pay attention. We're only going to say this once."85 Analogous with the work created by Goldsworthy, Gibson's work was designed to be experienced, or performed, in the moment, savored during the experience, and allowed to evaporate or be destroyed upon its having been played one time through.

This poem underscores that what is wrong with Kelley has the potential to be stretched beyond gardens and bowls of noodles to realms in which artistic decisions are triggered by software. For instance, are forces that are animated by algorithms or even the software of Agrippa's era analogous to or different from the forces of nature described in Kelley? Here the viewer still played an important role-many collectors of Gibson's work, for instance, kept the diskette in its book because to play it was to trigger its deterioration. It seems to me that copyright's scope should not depend on such formalist hair-splitting. Nor should the question of the scope of copyrightable subject matter in a work be set aside on technical grounds for lack of fixation. After all, important recent case law shows that copyright law's technicalities may lead parties to "engineer around" copyright law to exploit its loopholes, thus resulting in creating "Rube Goldberg-like contrivances" designed with no purpose other than technically - if not functionally - to avoid copyright infringement. ${ }^{86}$ In $A B C$ v. Aereo, the defendant's delivery of broadcast television served through thousands of dime-sized antennae was ultimately held to be infringing on more sound functionalist grounds, despite technically appearing to have complied with existing case law on the face of things. ${ }^{87}$ Copyright law should follow a functionalist approach with respect to fixation as well, so that works do not fail to receive copyright protection as a result of a technicality. Indeed, there may be larger substantive reasons to withhold copyright protection that more meaningfully serve copyright's purposes and help manage the proper boundaries for copyrightable subject matter.

\section{CONCLUSION}

In light of the importance of conceptual art over the past twenty to thirty years, and in the face of evidence of artistic practices that are ill-suited to a traditional understanding of the fixation requirement, Kelley's "inherently changing" standard is prohibitively broad. The scope of Kelley going forward should be at least somewhat limited by the fact that the work at issue, a garden, should not come within the scope of copyright's protectable subject matter. Courts should be wary of mechanically applying the sometimes-strained reasoning that the Kelley court employed in order to avoid reaching an outcome in which the garden was protected.

85. Tom Vitale, Amazing Disappearing Computer Book, NPR MORNING EDITION (Dec. 9, 1992) (transcript on file with Proquest).

86. WNET Thirteen v. Aereo, Inc., 712 F.3d 676, 697 (2d Cir. 2013) (Chin, J., dissenting).

87. Am. Broad. Co. v. Aereo, 134 S. Ct. 2498 (2014); Case Comment, ABC, Inc. v. Aereo, Inc., 128 HARV. L. REV. 371, 5, 66 (2014) (describing the court's "functionalist approach" and defining functionalism as an interpretive approach that "concentrates on what the technology does, not how it works, often focusing on the pragmatic, real-world effects rather than getting caught up in minutiae"). 
As courts consider disputes involving conceptual works of art, they may need guidance in the gulf established by Williams and Stern on the one hand (fixed: sufficiently permanent because repeating) and Kelley on the other hand (not fixed: essentially or inherently changing in nature). Along that spectrum between the poles of fixed and unfixed lies a range of works, changes within which may be the very point of the whole experience of the art. The taxonomy this Essay has offered suggests that there may be diverse legal treatments more suitable, based on prior case law, than the unstable one-size-fits-all approach of Kelley's "inherently changing" test, which has the effect of illogically excluding from copyright protection many different kinds of conceptual art. There may be many sound reasons to exclude conceptual art from copyright protection, perhaps chief among them that, often, conceptual art is driven by a concept, or idea, which copyright law remains committed to excluding. Fixation, however, especially as measured by Kelley's unstable and essentialist "inherently changing test," does not do a good job of marking the outer boundaries of copyright protection and, instead, encourages strained analogies and overly formalist analysis. Courts would do well to adopt Kelley cautiously, and in limited fashion, as they encounter works of conceptual art, and indeed, when they consider applying Kelley more broadly. 